\title{
Neurotization in brachial plexus injury - A 3 year experience in tertiary government institution
}

\author{
Rajeev M.P. ${ }^{1}$, Premkumar Sasi ${ }^{2}$, Pavitharan V.M. ${ }^{3}$, Pravin Yashwant Waykule ${ }^{4, *}$ \\ ${ }^{1}$ Professor and Head, ${ }^{2,3}$ Assistant Professor, ${ }^{4} \mathrm{MCh}$ Resident, Dept. of Neurosurgery, Government Medical College and Hospital, \\ Kozhikode, Kerala, India \\ * Corresponding Author: \\ Email: pravin_waykule@ rediffmail.com
}

\begin{abstract}
Introduction: Brachial plexus injuries are devastating injuries which leaves patient with useless upper limb. Many poor patients with these injuries attending the government hospitals in the hope of treatment, but very few government hospitals are operating such patients. Neurotization is very effective treatment among all other methods

Materials and Methods: This is retrospective study. Between February 2014 and May 2017, total 13 patients with brachial plexus injuries underwent neurotization in our department. Inclusion criterias were injuries to the upper spinal roots (C5, C6, C7), Surgery within 3 to 12 months of injury and Minimum follow up period of 12 months. Neurotization procedures were used for shoulder included transfer of spinal accessory nerve to suprascapular nerve in 12 patients, Somsak procedure in 4 patients, for elbow included Oberlin 1 procedure in 6 patients, oberline 2 procedure in 5 patients, Intercostal nerves to musculocutaneous nerve in 4 patients.

Results: Medical Research Council (MRC) scoring system was used to assess motor recovery. Results for shoulder and elbow function recovery seen as excellent in $1(7.69 \%)$ and 3(23.07\%), good in $1(7.69 \%)$ and $4(30.76 \%)$, fair in $5(38.46 \%)$ and 6 $(46.15 \%)$, poor in $6(46.15 \%)$ and 0 patients respectively

Conclusions: Neurotization is a simple and elegant procedure. Young patients with short denervation time, intraplexal and direct nerve transfers close to the target muscle decides the good functional outcome.
\end{abstract}

Keywords: Brachial plexus injury, Neurotization, Denervation time, Somsak and Oberline procedures.

\section{Introduction}

Brachial plexus injuries are devastating injuries resulting usually from high velocity motor bike accidents and usually involves younger population. In one report ${ }^{1}$ brachial plexus injuries were present in $4.3 \%$ of motor cycle accidents. Our institute we came across many such patients with loss of functions of UL and they have to live with useless limb for life long. Percentage of operating brachial plexus repair in government hospitals are very low. The timing of operation is very important factor, because neuromuscular junction degenerates around 2 years of duration. The best time period is first 3 to 6 months from the trauma. There are many surgical interventions for brachial plexus injuries like neurolysis, nerve repair, nerve grafting, pedicle muscle transfer and functioning free-muscle transfer, but neurotization is found to be very effective. This is a retrospective study of patients operated for brachial plexus injuries in our institute which mainly includes importance of denervation time, cost and outcome following multiple neurotization procedures used for repair.

\section{Materials and Methods}

This is a retrospective study of 13 patients (age group 5-57 years) with brachial plexus injury, who underwent neurotization procedure in Government Medical College, Kozhikode between February 2014 and May 2017.

\section{Inclusion Criterias:}

1. Irreparable injuries to the upper spinal roots ( $\underline{\mathrm{C} 5}$, C6, C7)

2. Surgery within 3 to 12 months of injury (except 1 patient 2 years after injury)

3. Minimum follow up period of 12 months. (except last 2 patients had 4 months follow up)

Preoperative work up: 1) History and clinical examination, 2) MRI Brachial plexus with cervical spine screening, 3) Orthopedic evaluation to r/o bony/ligamentous/vascular injury, 4) Nerve conduction study (NCS), 5) Electromyogram (EMG)

Table 1: Neurotization Procedures were used

\begin{tabular}{|l|c|c|}
\hline Shoulder & $\begin{array}{c}\text { Procedure } \\
\text { Spinal accessory nerve (SAN) } \\
\text { to Suprascapular Nerve (SSN) } \\
\text { (posterior approach) }\end{array}$ & 12 \\
\hline Elbow & $\begin{array}{c}\text { Radial nerve branch to long } \\
\text { head of triceps to anterior } \\
\text { branch of Axillary nerve } \\
\text { (Somsak procedure) }\end{array}$ & 4 \\
\hline $\begin{array}{c}\text { Ulnar nerve fascicle to the } \\
\text { biceps branch of } \\
\text { Musculocutaneous nerve } \\
\text { (Oberline 1 procedure (OBN } \\
\text { 1)) }\end{array}$ & 6 \\
\hline
\end{tabular}




\begin{tabular}{|c|c|c|}
\hline & $\begin{array}{c}\text { Median nerve fascicles to } \\
\text { brachialis branch of } \\
\text { Musculocutaneous nerve } \\
\text { (oberline 2 procedure (OBN } \\
\text { 2)) }\end{array}$ & 5 \\
\hline & $\begin{array}{c}\text { Intercostal nerves (ICN) (3rd, } \\
\text { 4th and 5th) to } \\
\text { musculocutaneous nerve } \\
\text { (MCN) }\end{array}$ & 4 \\
\hline
\end{tabular}

In 3 patients we did neurolysis along with neurotization

Surgical Techniques: All neurotization procedures are done under general anaesthesia

1) Spinal Accessory Nerve (SAN) to Suprascapular Nerve (SSN) (Posterior Approach): The patient was given lateral position. An incision was given just above and parallel to scapular spine [Fig. 1], and the trapezius was dissected free from it. The supraspinatus was retracted caudad to expose the transverse scapular ligament. The SSN was identified proximal to the ligament, beneath which the branch innervating the supraspinatus just emerges. This ligament should be incised in a cephalic to caudal direction to avoid the injury to the supraspinatus branch. The SSN was sectioned most proximally. The SAN was present underneath the trapezius, It was identified and cut most distally. Then two nerves were coapted directly without tension [Fig. 2]. This approach is helpful when the patient has a concomitant fracture of the upper portion of the scapula, in which the SSN may have a second lesion in the suprascapular notch in addition to C5-C6 avulsion; or when there is extensive scarred tissue in the supraclavicular region in which dissection may be very difficult.

2) Somsak Procedure: The patient was given lateral position. A vertical and slight oblique incision was given along the posterior border of deltoid. Axillary nerve was identified in the quadrilateral space. After emerging from this space, it gives branches to teres minor muscle and then few anterior branches and one posterior branch. The anterior branches supply to the deltoid which were dissected and cut most proximally. Radial nerve was identified between long and lateral head of triceps. The motor branch to long head of triceps was dissected and cut most distally. This branch was then rotated towards anterior branch of axillary nerve and coapted.

3) Oberline Procedures: Patient positioned supine and vertical incision given on anteromedial aspect of upper arm. The musculocutaneous nerve gives the motor branches to biceps and brachialis muscles which were identified and traced. The ulnar nerve was also identified almost at the same level [Fig. 3]. According to the topographical arrangement of peripheral location of motor fibres, one or two ulnar nerve fascicles were dissected and cut. This was coapted to the biceps branch of MCN with 8-0 nylon suture (Oberline1). Motor fascicles of the median nerve also dissected according to topographical arrangement and cut. This was coapted with the MCN branch to the brachialis (Oberline2).

4) Intercostal Nerves (ICN) (3rd, 4th and 5th) to Musculocutaneous Nerve (MCN): ICNs 3, 4, and 5 are explored through a transverse incision along the fourth rib, which extends from the posterior axillary line up to the mammary line [Fig. 4]. The lateral cutaneous branch is identified and traced proximally to reach its origin point where the main trunk of the ICN is found. The ICN is then freed distally out to the mammary line and then proximally until the posterior axillary line is reached then the ICN is transected near the mammary line. Then the axillary sheath was exposed and the lateral cord was identified. The musculocutaneous nerve was identified and traced upto its biceps motor branch. This branch is then cut most proximally from parent nerve and rotated towards ICNs [Fig. 5]. Nerve anatomosis was performed with the arm abducted to 90 degrees in external rotation

In all cases, operating microscope was used. 8-0 nylon sutures used for nerve coaptation. Nerve fascicles are created as per topographic arrangement of fibres. Tissue glue used in all cases.

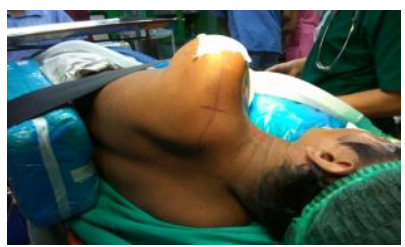

Fig. 1: Positioning and site of incision for SAN to SSN nerve transfer

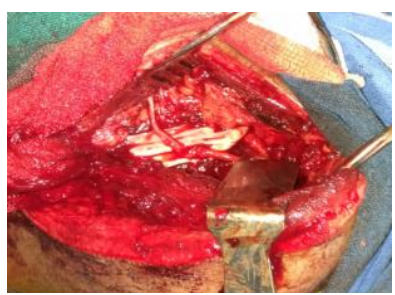

Fig. 2: The SAN (above) and SSN (below) coapted without tension

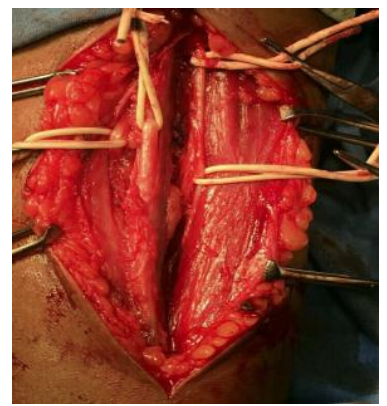

Fig. 3: Nerves exposed in Oberline procedures from medial to lateral ulnar nerve, median nerve and musculocutaneous nerve 


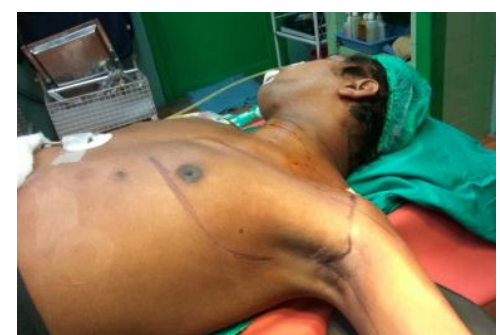

Fig, 4: Positioning and incision for ICN $(3,4,5)$ to MCN transfer

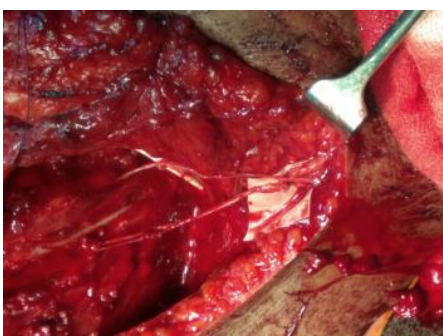

Fig. 5: Exposure of nerves ICN 3 and 4 (medially) and MCN (laterally)

Table 2: Details of neurotisation for shoulder and elbow functions

\begin{tabular}{|l|c|c|c|}
\hline Pt. No. & Roots involved & Shoulder & Elbow \\
\hline 1 & C5,C6 and C7 & -- & ICN $\left(3^{\text {RD }}\right)-$ MCN \\
\hline 2 & C5, C6 & SAN - SSN & OBN 1 \\
\hline 3 & C5, C6 & SAN - SSN, SOMSAK & OBN 1 \\
\hline 4 & C5, C6 & SAN - SSN & OBN 1, OBN 2, \\
& & & ICN $(2,3,4)-$ MCN \\
\hline 5 & $\begin{array}{c}\text { Erb's palsy (C5,C6 } \\
\text { birth injury) }\end{array}$ & $\begin{array}{c}\text { Neurolysis + } \\
\text { SAN - SSN }\end{array}$ & OBN 1 \\
\hline 6 & C5, C6 & SAN - SSN, SOMSAK & OBN 1 \\
\hline 7 & C6, C7 & SAN - SSN & ICN $(4,5)-$ MCN \\
\hline 8 & C6, C7 & SAN - SSN, SOMSAK & OBN 1, OBN 2 \\
\hline 9 & C5, C6 & SAN - SSN, SOMSAK & OBN 2 \\
\hline 10 & C5, C6 & SAN - SSN & OBN 2 \\
\hline 11 & C5, C6 & SAN - SSN & OBN 2 \\
\hline 12 & C6, C7 & Neurolysis + & ICN (3,4) - MCN \\
& & SAN - SSN & -- \\
\hline 13 & C8, T1 & Neurolysis + & SAN - SSN \\
\hline
\end{tabular}

During post-operative period arm was flexed and strapped to chest for 3 weeks followed by gradually increasing passive exercises. Electrical stimulation was also used till adequate power (M3) was achieved.
All patients were followed up at 3-months intervals. The pre and post op motor power was examined using the British Medical Research Council (MRC) Grading System (Table 3)

Table 3: Modified British MRC scale for manual muscle testing

\begin{tabular}{|l|c|}
\hline Modified MRC grade & Degree of strength \\
\hline 5 & Normal power \\
\hline $5-$ & Equivocal, just detectable weakness \\
\hline $4+$ & Definite but slight weakness \\
\hline 4 & Able to move the joint against combination of gravity and \\
some resistance
\end{tabular}

\section{Result}

Nerve transfer was done in 13patients with upper brachial plexus injury. $12(92.3 \%)$ were male and one (7.69\%) was female in the age group 5-57 years (mean
33.5 years). The right side was involved in $5(38.4 \%)$ and the left side was involved in $8(61.5 \%)$ patients.The mean denervation time was 7.5 months (range: 3 to 12 months), except one patient which had denervation 
period of 24 months still he showed improvement in elbow function. In 3 patients, the brachial plexus injury was associated with shoulder dislocation, 2 had malunited coracoid process fracture. One patient had subclavian artery injury. Motorcycle accident was the most common cause of brachial plexus injury and seen in12 patients $(92.3 \%)$. One patient was of Erbs palsy (7.69\%). All patients had traction injuries. The postoperative motor results were assessed as poor, fair, good and excellent as per classification proposed by Terzis et al. ${ }^{3}$ depending on the muscle grade achieved (Table 4).

Table 4: Post op functional evaluation

\begin{tabular}{|l|c|c|c|}
\hline Results & $\begin{array}{c}\text { Muscle } \\
\text { Grade }\end{array}$ & $\begin{array}{c}\text { Shoulder } \\
\text { Function }\end{array}$ & $\begin{array}{c}\text { Elbow } \\
\text { Function }\end{array}$ \\
\hline Poor & M0 to M1 & $6(46.15 \%)$ & 0 \\
\hline Fair & M2 to M3 & $5(38.46 \%)$ & $6(46.15 \%)$ \\
\hline Good & M3+ to M4 & $1(7.69 \%)$ & $4(30.76 \%)$ \\
\hline Excellent & M4+ to M5 & $1(7.69 \%)$ & $3(23.07 \%)$ \\
\hline
\end{tabular}

[Fig. 6,7,8,9] shows post-operative improvement in motor power of shoulder and elbow joint.

Time duration required for each procedures: SAN SSN - $2 \mathrm{hr}$, Somsak procedure - $90 \mathrm{mins,} \mathrm{Oberline}$ procedures $-1 \mathrm{hr}$ and ICN - MCN - $2 \mathrm{hr}$.

Treatment cost required is less than 10,000 (tissue glue 8,000 + prolene 8-0 1000). Most of the patients we operated at free of cost under govt insurance schemes.

Post op complications:

One patient developed surgical site hematoma, which was drained. No other significant complications were occurred.

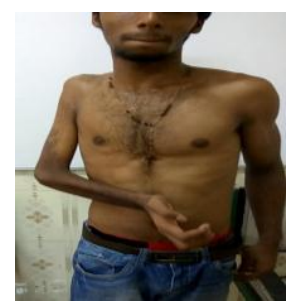

Fig. 6: Post-operative improvement after 12 months

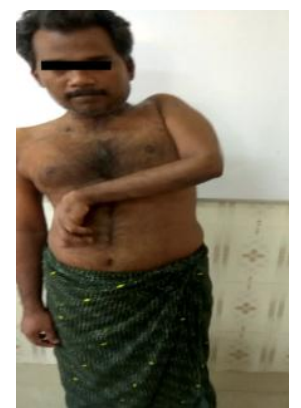

Fig. 7: Post-operative improvement after 18 months

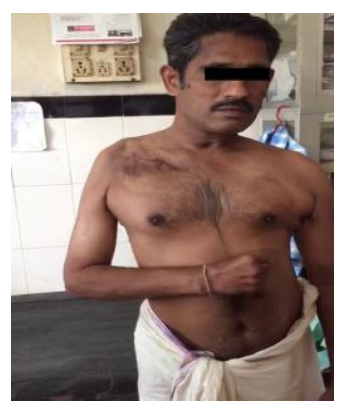

Fig. 8: Post-operative improvement after 25 months

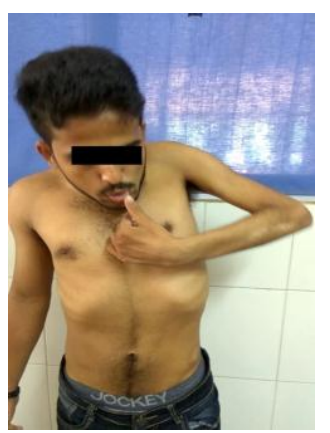

Fig. 9: Post-operative improvement after 34 weeks

Table 5: Clinical details

\begin{tabular}{|l|c|c|c|c|c|c|}
\hline Pt. No. & Age (yr) & sex & $\begin{array}{c}\text { denervation } \\
\text { time(months) }\end{array}$ & $\begin{array}{c}\text { Follow } \\
\text { up(months) }\end{array}$ & $\begin{array}{c}\text { Shoulder } \\
\text { power }\end{array}$ & $\begin{array}{c}\text { Elbow } \\
\text { power }\end{array}$ \\
\hline 1 & 25 & $\mathrm{M}$ & 12 & 37 & $\mathrm{M} 0$ & $\mathrm{M} 3+$ \\
\hline 2 & 18 & $\mathrm{M}$ & 4 & 34 & $\mathrm{M} 3$ & $\mathrm{M} 4$ \\
\hline 3 & 29 & $\mathrm{M}$ & 6 & 27 & $\mathrm{M} 3+$ & $\mathrm{M} 4+$ \\
\hline 4 & 57 & $\mathrm{M}$ & 10 & 25 & $\mathrm{M} 2$ & $\mathrm{M} 3$ \\
\hline 5 & 5 & $\mathrm{~F}$ & 9 & 24 & $\mathrm{M} 4+$ & $\mathrm{M} 4+$ \\
\hline 6 & 45 & $\mathrm{M}$ & 3 & 18 & $\mathrm{M} 2$ & $\mathrm{M} 4+$ \\
\hline 7 & 54 & $\mathrm{M}$ & 12 & 21 & $\mathrm{M}$ & $\mathrm{M} 2$ \\
\hline 8 & 53 & $\mathrm{M}$ & 7 & 20 & $\mathrm{M} 3$ & $\mathrm{M} 3$ \\
\hline 9 & 34 & $\mathrm{M}$ & 8 & 18 & $\mathrm{M} 2$ & $\mathrm{M} 3$ \\
\hline 10 & 20 & $\mathrm{M}$ & 4 & 13 & $\mathrm{M} 1$ & $\mathrm{M} 3+$ \\
\hline
\end{tabular}




\begin{tabular}{|c|c|c|c|c|c|c|}
\hline 11 & 36 & $\mathrm{M}$ & 6 & 12 & M1 & M3 \\
\hline 12 & 25 & $\mathrm{M}$ & 12 & 4 & M1 & M3+ \\
\hline 13 & 20 & $\mathrm{M}$ & 24 & 4 & M0 & M3 \\
\hline
\end{tabular}

\section{Discussion}

Brachial plexus injury is a devastating injury and involves $15-20 \%$ of supraclavicular injuries. ${ }^{4}$ These injuries leave the patients with useless upper limb. Repair of these injuries are very crucial to regain the functions of upper limb. There are many methods available for nerve repair, which are mentioned earlier, but nerve transfer is found to be very superior in every aspect. During the situations like root avulsion, extensive fibrosis around the plexus, neurotization is found to be the only valid option.

Neurotization helps to restore mainly elbow and shoulder function. Many donor nerves from intraplexal or extraplexal origin are used. For elbow function restoration we used ulnar nerve, median nerve, ${ }^{5}$ intercostal nerves $(3,4,5)$ (extraplexal) ${ }^{6-8}$ ICN to MCN transfer is little challenging and may be sometimes associated with life threatening complications, ${ }^{9}$ though we haven't encountered any. Oberline procedures has produced the most promising results. Donor nerves are intraplexal origin and are in healthy state. Improvement in post-operative period is very faster in elbow function compared to shoulder. Other donor nerves can be used are medial pectoral nerve, phrenic nerve, thoracodorsal nerve.

Nerve transfer to shoulder also provided good range of shoulder abduction and stability. ${ }^{10,11}$ SAN to SSN provided almost 45 to $60^{\circ}$ abduction and some external rotation. We have preferred posterior approach as reason was explained earlier. In some patients we did Somsak procedure depending upon the viability of donor nerves. This procedure also contributed additional improvement in shoulder function.

Thus we have observed that intraplexal multiple transfers produced much better results than extraplexal single nerve transfer. In some patients due to nonavailability of intraplexal donor nerves we have used extraplexal donor nerves (eg. ICN), still they showed adequate improvement. Younger patients showed good recovery compared to older one. Denervation time is also important factor. Patients with shorter denervation time had good recovery than other. In one patient with denervation time 24 months we did SAN to SSN nerve transfer and neurolysis, surprisingly patient has fair improvement in elbow function.

\section{Conclusion}

Brachial plexus injury is a devastating type of injury. It is often encountered injury in road traffic accidents and is neglected many a times due to various factors. These patients are mostly young males and the sole earning member of the family and may have to live with a useless limb life-long, which places both physical and financial burden on the family as well as society. Neurotization is a simple and elegant procedure and should always be considered in severe upper plexus injuries. The results of surgery together with physiotherapy are rewarding if done within the stipulated time period. It is an affordable procedure and cost in govt. hospital is less than 10,000/-. Prognostic factors for good functional outcome are young patient with short denervation period, intraplexal nerve transfers, direct transfers, Selective neurotization close to the target muscles, use of multiple donor nerves to restore a single function. In selected cases additional neurolysis also shows good results. Proper physiotherapy has a very important role to play in the recovery of these injuries.

\section{References}

1. Midha R. Epidemiology of brachial plexus injuries in a multitrauma population. Neurosurgery. 1997;40:1182e1189.

2. Medical Research Council.Aids to the Examination of the Peripheral Nervous System. London: Bailliere Tindall; 1986.

3. Terzis JK, Vekris MD, Soucacos PN. Outcomes of brachial plexus reconstruction in 204 patients of devastating paralysis. Plast Reconstr Surg. 1999;104:1221-40.

4. Alnot JY. Traumatic brachial plexus lesions in the adult. Indications and results. Hand Clin. 1995;11:623-31.

5. Oberlin C, Béal D, Leechavengvongs S, Salon A, Dauge MC, Sarcy JJ. Oberlin Nerve transfer to biceps muscle using a part of ulnar nerve for C5-C6 avulsion of the brachial plexus: anatomical study and report of four cases. J Hand Surg Am. 1994;19:232-73.

6. Chuang DC, Lee GW, Hashem F, Wei FC. Restoration of shoulder abduction by nerve transfer in avulsed brachial plexus injury: evaluation of 99 patients with various nerve transfers. Plast Reconstr Surg. 1995;96:122-8.

7. Chuang DC, Yeh MC, Wei FC. Intercostal nerve transfer of the musculocutaneous nerve in avulsed brachial plexus injuries. J Hand Surg Am. 1992;17:808-22.

8. Krakauer JD, Wood MB. Intercostal nerve transfer for brachial plexopathy. J Hand Surg Am. 1994;19:829-35.

9. Waikakul S, Wongtragul S, Vanadurongwan V. Restoration of elbow flexion in brachial plexus avulsion injury: comparing spinal accessory nerve transfer with intercostals nerve transfer. J Hand Surg Am. 1999;24:571-7.

10. Narakas AO. In: Thoughts on neurotization or nerve transfers in irreparable nerve lesions. Terzis JK, editor. Philadelphia Saunders: Microreconstruction of nerve injuries;1987. pp.447-54.

11. Kawai H, Kawabata H, Masada K, Ono K, Yamamoto K, Tsuyuguchi $\mathrm{Y}$, et al. Nerve repairs for traumatic brachial plexus palsy with root avulsion. Clin Orthop Relat Res. 1988;237:75-86. 